2 Roberts, S.W., PANDRAUd, G., LUFF, B.J., BOWDEN, C., ANNETTS, P.J., BOZEAT, R.J., FULLER, S., DRAKE, J., JACKSON, M., and ASGHARI, M.: 'NFOEC'. Denver, CO, USA, 2000, Paper 08000

3 NAYDENKOV, M., and JALALI, B.: 'Proc. SPIE'. Photonics West conference, San Jose, CA, January 2000, Vol. 3936, p. 33

4 DIAL, O., CHENG, C.C., and SCHIERER, A.: 'Fabrication of high density nanostructures by electron beam lithography', J. Vac. Sci. Technol., 1998, B16, p. 3887

5 RALSTON, J.M., and CHANG, R.K.: 'Spontaneous-Raman-scattering efficiency and stimulated scattering in silicon', Phys. Rev. B, 1970, B2 (6), p. 1858

6 SCHMIDTCHEN, J., SPLetT, $A$, SChuppert, B., PETERMANN, K., and BURBACH, G.: 'Low loss single mode optical waveguides with large cross-section in silicon-on-insulator', Electron. Lett., 1991, 27, (16), p. 1486

7 STOLEN, R.H., and IPPEN, E.P.: 'Raman gain in glass optical waveguides', Appl. Phys. Lett., 1973, 22, (6), p. 276

8 REINTJES, J.F., and MCGRODDY, J.C.: "Indirect two-photon transitions in Si at $1.06 \mu \mathrm{m}$ ', Phys. Rev. Lett., 1973, 30, (19), p. 901

9 AGRAWAL, G.: 'Nonlinear fibcr optics' (Academic Press, London, 2001, 3rd end.)

10 GRIMSDITCH, M., and CARDONA, M.: 'Absolute cross-section for Raman scattering by phonons in silicon', Phys. Statu. Solidi. (B), 1980, 102, p. 155

11 IPPEN, E.P., and STOLEN, R.I.: 'Stimulated Brillouin scattering in optical fibers', Appl. Phys, Lett., 1972, 21, (11), p. 539

\section{Low-threshold current GaAsSb/GaAs quantum well lasers grown by solid source molecular beam epitaxy}

Po-Wei Liu, Ming-Han Lee, Hao-Hsiung Lin and Jhe-Ren Chen

Low threshold current density GaAsSb/GaAs quantum well lasers were grown on GaAs substrate using solid source molecular beam epitaxy. The laser emits $1.28 \mu \mathrm{m}$ light output and demonstrates a very low threshold current density of $210 \mathrm{~A} / \mathrm{cm}^{2}$.

Introduction: $1.3 \mu \mathrm{m}$ semiconductor lasers grown on GaAs substrates are of great interest recently because they have been recognised to be the key light sources for the optical communications in the near future. The active media used for GaAs-based $1.3 \mu \mathrm{m}$ lasers include InGaAsN [1], quantum dots [2], and GaAsSb quantum wells (QWs) [3-5]. Among these materials, strained GaAsSb/GaAs QWs grown on GaAs substrate, which exhibit a staggered type-II band alignment, possess the potential of emitting a wavelength longer than those corresponding to the fundamental band gap energies of each constituent. The GaAsSb QW lasers reported were grown by growth methods such as metal organic vapour phase epitaxy (MOCVD) [3] and mostly by gas source molecular beam cpitaxy (GSMBE) [4, 5]. Although good results have been reported for GaAsSb lasers grown by GSMBE and MOCVD, fewer good results were obtained by solid source molecular beam epitaxy (SSMBE). In this Letter, we report $\mathrm{GaAsSb} / \mathrm{GaAs}$ double quantum well lasers grown by SSMBE utilising a cracked $\mathrm{Sb}$ monomer $\left(\mathrm{Sb}_{1}\right)$ for $\mathrm{Sb}$ source. The high quality of the laser is manifested by the very low threshold current density measured in the broad area devices.

Experiment: The lasers were grown on $n^{+}$GaAs (100) substrate by SSMBE. Besides the conventional Ga beam, a cracked Sb monomer and uncracked As tetramer were used in the growth of the GaAsSb. The improvement in the optical quality of the Sb-containing compound semiconductor by using $\mathrm{Sb}_{1}$ instead of $\mathrm{Sb}_{4}$ has been reported in [6]. The active region of the laser, which was grown at $500^{\circ} \mathrm{C}$, consists of two $7 \mathrm{~nm} \mathrm{GaAs} \mathrm{ng}_{0.66} \mathrm{Sb}_{0.34}$ QWs embedded in GaAs barriers. Step-confined $0.1 \mu \mathrm{m} \mathrm{Al}_{0.3} \mathrm{Ga}_{0.7} \mathrm{As}$ was used for the waveguide layers and $1.5 \mu \mathrm{m} \mathrm{Al} \mathrm{A}_{0.6} \mathrm{Ga}_{0.4} \mathrm{As}$ was used for cladding layers. The AlGaAs layers and a $0.5 \mu \mathrm{m}$ buffer $n^{+} \mathrm{GaAs}$ were grown at $580^{\circ} \mathrm{C}$. $50 \mu \mathrm{m}$ wide broad area lasers with different cavity lengths were fabricated by using standard photolithography, wet-etching and metallisation processes.

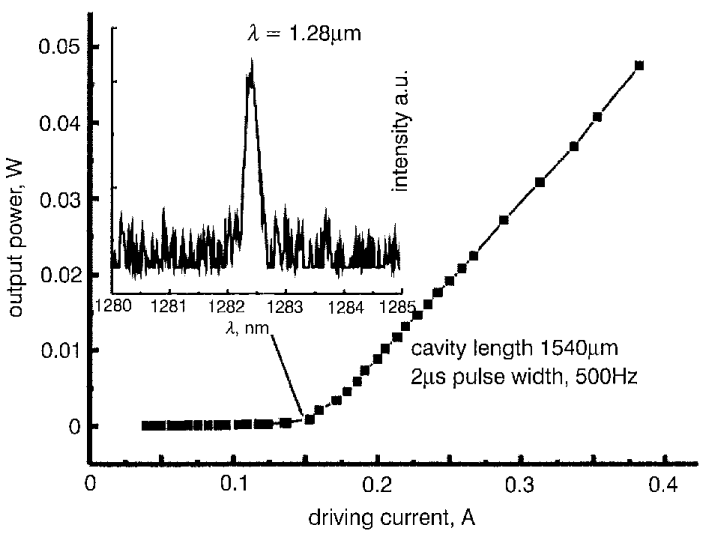

Fig. 1 Light against current characteristic of 1.54 mm-long GaAsSb/GaAs QW laser

Inset: Lasing spectra of GaAsSb/GaAs QW laser.

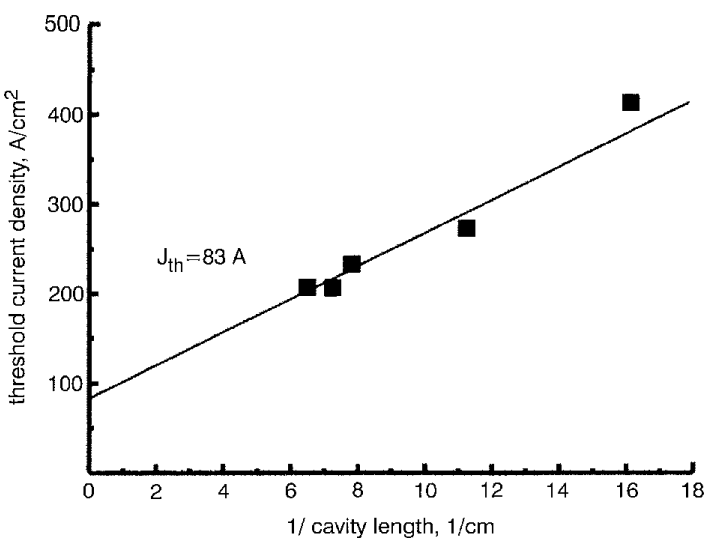

Fig. 2 Threshold current densities against inverse cavity length

Characteristics of laser: The fabricated lasers were tested under $2 \mu \mathrm{s}$ pulsed mode. Fig. 1 shows the light output power against current characteristics of a $1.54 \mathrm{~mm}$ long laser. The threshold current and threshold current density are $162 \mathrm{~mA}$ and $210 \mathrm{~A} / \mathrm{cm}^{2}$ respectively. The result is close to the lowest values reported for GaAsSb lasers [3]. However, as can be seen in the inset of Fig. 1, our laser emits a longer wavelength at $1.28 \mu \mathrm{m}$ in comparison to the $1.19 \mu \mathrm{m}$ reported in [3]. In fact, the threshold current density is among the lowest valucs reported around the $1.3 \mu \mathrm{m}$ region for GaAs-based QW lasers including InGaAs and InGaAsN QWs. Fig. 2 shows the cavity length dependence of the threshold current density. The threshold current density of the infinite cavity length extrapolated from the data is only $83 \mathrm{~A} / \mathrm{cm}^{2}$. The dependence of inverse external quantum efficiency against cavity length is shown in Fig. 3. The internal quantum efficiency is $62.8 \%$ and the internal loss fitted is $3.45 \mathrm{~cm}^{-1}$ The improvement of the threshold current density is attributed to be the use of $\mathrm{Sb}_{1}$ as the Sb source in the growth of the GaAsSb layers. The temperature characteristics of our grown laser were measured from 25 to $85^{\circ} \mathrm{C}$, and the characteristic temperature is $60 \mathrm{~K}$, which is the typical value for GaAsSb laser reported in the literatures [3-5]. The low internal efficiency and characteristic tempcrature are believed to be due to the type-II structure of the GaAsSb/GaAs QW. In the type II quantum well, the spatially separated electrons and holes result in a spacc charge field that produces an approximately triangular electron QW in the conduction band of the GaAs barricr. As the density of the accumulated electron increases, the accordingly enhanced electric field will push the electrons toward the interface. When the electrons reach a considerable density, there will be a sufficient gain to stimulate lasing action [7]. Though the spatial separation of the electrons and holes gives a lower peak gain, it does not mean that the threshold current will be increased because the spontaneous emission is also inhibited as pointed out in [8]. However, significant blue shift of the lasing wavelength compared to the low excitation conditions will occur due 
to the increase of the clectron quantisation energy in the triangular well. In addition, the confinement of the electron near the quantum well interface depends mainly on the band distortion of the charge-induced triangular well. Thus, the weak confinement of the triangular barrier may result in a higher carricr leakage and lower injection efficiency. The argument can also explain the low characteristic temperature measured in the $\mathrm{GaAsSb} / \mathrm{GaAs}$ lasers.

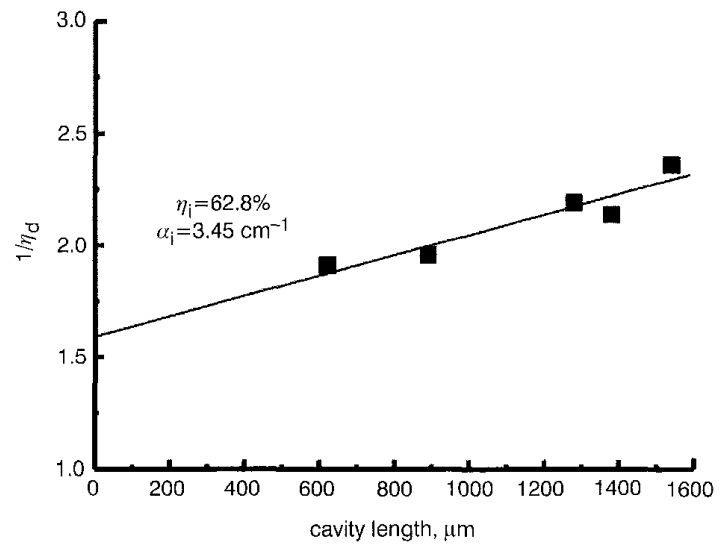

Fig. 3 Cavity length dependence of inverse external quantum efficiency

Conclusion: In conclusion, we have successfully grown a low threshold current density GaAsSb/GaAs double QW laser by using SSMBE. The laser emits a $1.28 \mu \mathrm{m}$ light output. A very low threshold current density of $210 \mathrm{~A} / \mathrm{cm}^{2}$ is reported. The low threshold current density is attributed to the use of $\mathrm{Sb}_{1}$ as the $\mathrm{Sb}$ source in the growth of GaAsSb layers. Internal quantum efficiency and internal loss are measured to be $62.8 \%$ and $3.45 \mathrm{~cm}^{-1}$, respectively. The characteristic temperature of the laser is $60 \mathrm{~K}$. The lower efficiency and characteristic temperature compared to conventional InGaAs/GaAs type-I QW lasers are briefly discussed and attributed to the nature of the type-II band strueture in GaAsSb/GaAs QW lasers.

Acknowledgments: This work was supported by the National Science Council of the Republic of China under contract number NSC 90-2215-E-002-036 and the MOE Program for Promoting Academic Excellent of Universities under grant number 89-N-FA01-2-4-3.

\section{(C) IEE 2002}

14 August 2002

Electronics Letters Online No: 20020932

DOI: 10.1049/el:20020932

Po-Wei Liu, Ming-Han Lee, Hao-Hsiung Lin and Jhe-Ren Chen (Room 419, Graduate Institute of Electronic Engineering and Department of Electrical Engineering, National Taiwan University, No. 1, Sec. 4, Roosevelt Road, Taipei, Taiwan, Republic of China)

\section{References}

1 TANSU, N., and MAWST, J.L.: 'Low-threshold strain-compensated InGaAs(N) $(\lambda=1,19-1.31 \mu \mathrm{m})$ quantum-well lasers', IEEE Photonics Technol. Lett., 2002, 14, pp. 444-446

2 QIU, Y., GOGNA, P., FOROUIIAR, S., STINTZ, A., and LESTER, L.F: 'Ilighperformance InAs quantum-dot lasers near $1.3 \mu \mathrm{m}$ ', Appl. Phys. Lett., 2001, 79, pp. 3570-3572

3 RYU, S.W., and DAPKUS, P.D.: 'Low threshold current density GaAsSb quantum well $(\mathrm{QW})$ lasers grown by metal organic chemical vapour deposition on GaAs substrates', Electron. Lett, 2000, 36, pp. 1387-1388

4 YAMADA, M, ANAN, T., TOKUTOME, K., KAMEI, A., NISHI, K., and SUGOU, S.: 'Low-threshold operation of $1.3 \mu \mathrm{m}$ GaAsSb quantum-well lasers directly grown on GaAs substrates', IEEE Photonics Technol. Lett., 2000,12 , pp. $774-776$

5 QUOCH, K, KLIPER, D.C., CUNNINGHAM, J.E., DINU, M., and SNAH, J: 'Continuous-wave operation of $1.3 \mu \mathrm{m}$ GaAsSb-GaAs quantum-well vertical-cavity surface-emitting laser at room temperature', IEEE Photonics Technol. Lett., 2001, 13, pp. 921-923

6 XIE, Q., VAN NOSTRAND, J.E., JONES, R.L., SIZI:LOVE, J., and LOOK, D.C.: 'Electrical and optical properties of undoped GaSb grown by molecular beam epitaxy using cracked $\mathrm{Sb}_{1}$ and $\mathrm{Sb}_{2}, J$ Cryst. Growth, 1999, 207, pp. $255-265$

7 LIU, G., CHUANG, S.L., and PARK, S.H.: 'Optical gain of strained $\mathrm{GaAsSb} / \mathrm{GaAs}$ quantum-well lasers: A self-consistent approach', J. Appl. Phys., 2000, 88, pp. 5554-5561

8 CHOW, W.W, and SCHNEIDER, H.C.: 'Charge-separation effects in $1.3 \mu \mathrm{m}$ GaAsSb type-Il quantum-well laser gain', Appl. Phys. Lett., 2001, 78, pp. $4100-4102$

\section{Nd-doped tellurite glass microsphere laser}

\author{
K. Sasagawa, K. Kusawake, J. Ohta and M. Nunoshita
}

Continuous-wave oscillation in a Nd-doped tellurite glass microsphere laser at $1.06 \mu \mathrm{m}$ has been successfully demonstrated for the first time. Microspheres with diameters of 50 to a few hundred micrometres are fabricated by melting using an electric heater. Imission spectra reveal that the devices exhibit resonances corresponding to whispering gallery modes.

Introduction: In a microsphere, light is confined at the surface by repeated total internal reffection, leading to whispering gallery mode (WGM) resonance with high quality factor $(Q)$. Nonlinear effects at low incident power and lasers with very low threshold can be realised based on these characteristics. Lascr oscillation has already been demonstrated using microdroplets [1], polymer spheres [2], and glass microspheres [3-6].

Owing to the high transparency of glass, glass microspheres with high-Q (up to $10^{\text {t) }}$ for fused silica microspheres) have been successfully fabricated $[3,4]$. Laser oscillation has to date been reported for microspheres made of silica $[3,4]$, phosphate [5] or fluoride glass [6] doped with rare-earth ions. Spillane et al. also recently demonstrated a fused silica microsphere as a low-threshold Raman laser [7].

The present authors have focused on laser oscillations in tellurite glass. Tellurite glass doped with rare-earth ions will provide more potential laser lines than silica since the phonon energy in tellurite glass is lower than in silica glass. The stability and chemical durability of tellurite glass are also superior to fluoride glass. Furthermore, as tellurite glass has a high nonlinear refractive index, it is potentially applicable to a range of nonlinear optical devices [8].

In this Letter, we present the fabrication of Nd-doped tellurite glass microspheres and the first observations of laser oscillation in tellurite microspheres corresponding to the optical transition from ${ }^{4} \mathrm{~F}_{3 / 2}$ to ${ }^{4} \mathrm{I}_{11 / 2}$ at $1.06 \mu \mathrm{m}$.

Experiment: Tellurite glass spheres were prepared as follows. Highpurity commercial oxides were employed as starting materials (99.99 and $99.999 \%$ purc). Powders of these materials, weighed to the composition of $10 \mathrm{Li}_{2} \mathrm{O}-20 \mathrm{ZnO}-70 \mathrm{TeO}_{2}-1 w \mathrm{t} \% \mathrm{Nd}_{2} \mathrm{O}_{3}$, were mixed and placed in a platinum crucible. The crucible was heated at $900^{\circ} \mathrm{C}$ for $20 \mathrm{~min}$ in an electric furnace. Glass wires with diameters from 10 to a few hundred micrometres were fabricated by dipping a platinum wirc into the melt and drawing slowly. Quasi-spherical structures of 50 to a few hundred micrometres in diameter were then formed by surface tension when the end of the glass wire was heated and melted by a Kanthal wire heater. The wire attached to the sphere was found not to affect the WGMs that occur near the equator of the sphere and was convenient for manipulation. Fig. $1 a$ shows a scanning clectron microscope image of the microsphere obtaincd in this study. The image reveals a smooth surface without observable defects.

The schematic diagram of the experimental setup for lasing observation is shown in Fig. 2. The microsphere was pumped by a Ti:sapphire laser tuned to $800 \mathrm{~nm}$. The incident beam was focused via a microscope objective lens $(20 \times$, numerical aperture 0.40$)$ such that the beam irradiated a point slightly offset from the centre of the sphere. The image of a pumped microsphere is shown in Fig. $1 b$. The output from the sphere was coupled into a multimode optical fibre. The spectrum of 